\title{
Crafting the Architectural Measured Drawings
}

THEORY

\author{
Serra Akboy-lik
}

ABSTRACT - For centuries, measured drawings have been the major communication medium to acquire an understanding of the built environment and to deliver ideas of construction and design. The value of measured drawings as educational tools to learn about the architectural context as well as signifiers of the cultural values have transcended the importance of these two-dimensional illustrations as ephemeral depictions of building forms and materials. In the midst of an architectural culture increasingly utilizing three-dimensional virtual surrogates along with the state-of-the-art surveying and representation methodologies, however, the production of measured drawings have been relegated to a narrower focus in the documentation projects. The methodological path to produce measured drawings carries similar traits with how ethnographers create thick descriptions of cultural signifiers. Reflecting on measured drawings as an account of "thick description," this essay addresses architectural documentation.

Keywords: measured drawings, HABS, surveying, laser scanning, Clifford Geertz

Architects' drawings, either focusing on existing materials or projecting imagined ideas, are analytical and interpretive. The process of drawing includes a mental cycle of documenting, seeing, knowing, and experiencing. The Italian architect Carlo Scarpa (1906-1978) famously stated that drawing allows him to see: "I place things in front of me, on 
the paper, so I can see them. I want to see, therefore, I draw. I can see an image only if I draw it."1 Making drawings of the built environment, in this context, is often considered as simply a technique of basic visualization of the existing architectural fabric and a passive form of recording. ${ }^{2}$ Drawing and documenting, on the contrary, have a long tradition in the architectural culture, which allow architects to conceive existing building forms and materials, and to develop design inquiries.

Even though associated with stark modernist design, Charles Edouard Jeanneret (Le Corbusier, 1887-1965), for example, distinctively emphasized the value of learning by measuring and drawing the existing architectural examples. ${ }^{3}$ The development of Le Corbusier's distinct style stems from his travels to Europe and Mediterranean between 1907 and 1911, where he constantly made sketches of his surroundings. Le Corbusier's passion of exploration of the pleasing spatial relationships as well as structural qualities culminated in a series of magnificent drawings of ancient ruins, details of interior spaces, and landscapes, annotated with careful notes and dimensions. In his writings, Le Corbusier even advised carrying a tape measure to check the prevailing geometric guides as the sources of architectural design. ${ }^{4}$ Le Corbusier's sketches involve a process of abstraction of the inherent attributes of the architectural context, as investigations of mass, surface, and plan, articulated in his widely recognized book Towards a New Architecture. ${ }^{5}$

\section{DRAWING THE BUILT ENVIRONMENT}

In the architectural culture, two-dimensional measured drawings are the formalized product of documentation, which are produced for preservation pursuits. Measured drawings are made years after a building is constructed, showing the existing condition of the architectural setting at the time of documentation. Figure 1 illustrates a measured drawing of the Montezuma Castle, Camp Verde, Arizona, U.S. delineated in 2003. The elevation drawing shows a cliff dwelling, constructed by Sinagua people in the late twelfth century. Having a measurable record of the architectural heritage, such as the depiction of the vertical qualities of the façade of the castle, provides the information to understand the significance of the heritage fabric, to record the existing conditions of the asset, and to interpret the qualities for informed decisions on the preservation of the built environment.

Although Le Corbusier's favorite recording apparatus of tape measure is still a part of the documentation toolbox, to provide an accurate measurable surrogate of the built environment, architects extensively use advanced recording and documentation practices. Methodologies such as photogrammetric devices, three-dimensional laser scanners, and total station instruments enable inquirers to collect highly accurate 


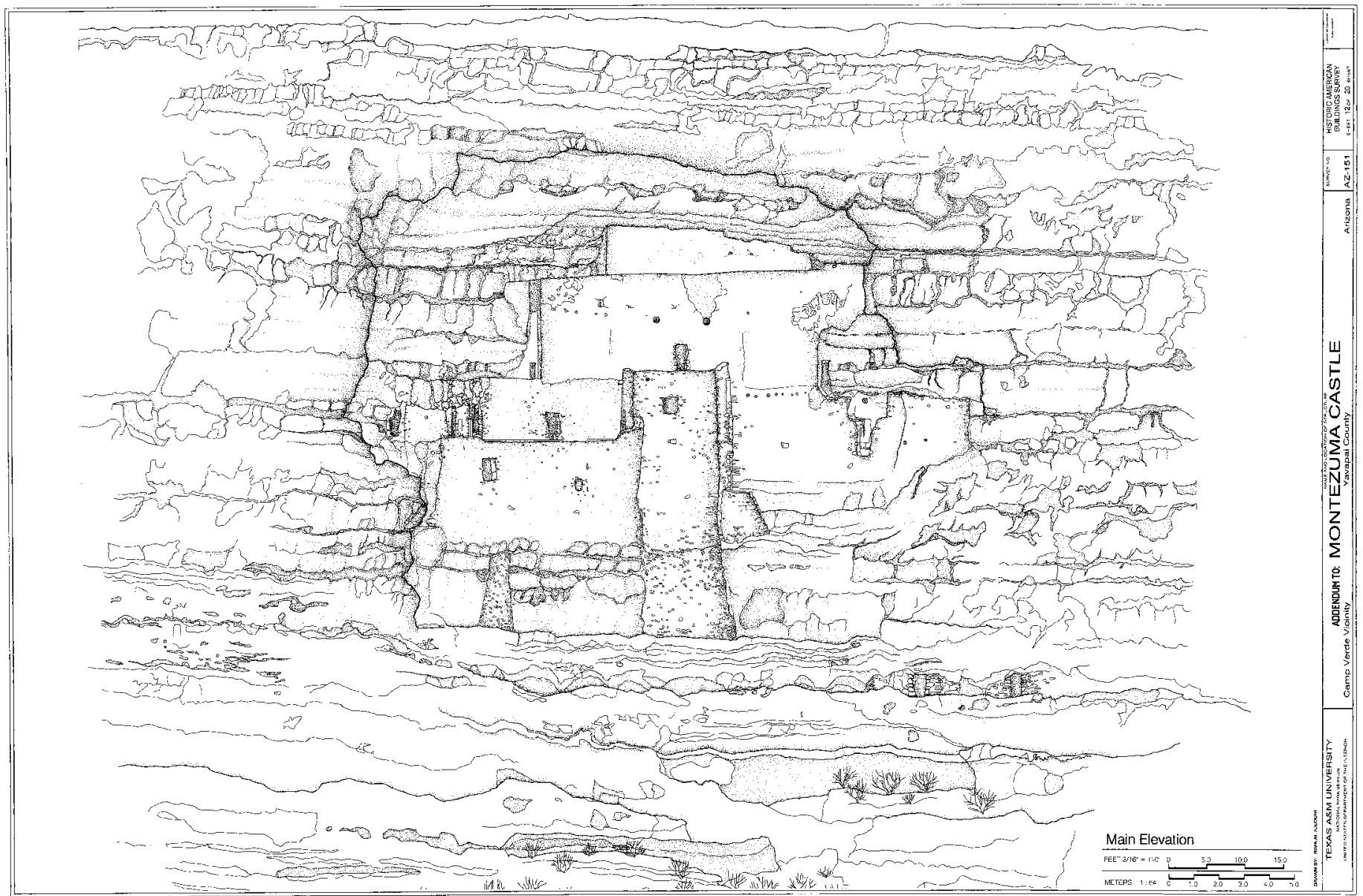

Figure 1. The elevation drawing of Montezuma Castle, Camp Verde, Arizona, U.S. (HABS ARIZ, 13-CAMV.V, 1- (sheet 12 of 20)).

measurements from the surfaces remotely. The exactitude of the digital field data has significant advantages in a preservation project because the virtual surrogate can be translated into different formats, such as a template for measured drawings, volumetric input for mass analyses, or metric data to calculate structural deformations. To collect measurements, moreover, considerably reduces the cost of the fieldwork since inquirers can undertake a building survey in a couple of days fieldwork compared to weeks long hand measuring.

While the benefits of advanced surveying technologies for the logistical and operational scheme of a documentation project are palpable, these applications culminate in a certain level of disengagement with the built environment. The automated collection of the digital data circumvents the creative process of making field drawings, which is integral for field analysis and discovery. Albeit the cognitive benefits of establishing a close relationship with the built environment through drawing, in the current practice, inquirers, physically removed from the building, allocate most of the field time dealing with the accompanying hardware and software achieve a digital surrogate of the architectural fabric. ${ }^{6}$ Through manipulating diverse system parameters, such as the location of the surveying stations or the absolute position of the digital survey points, architects negotiate the virtual surrogates to extract the information that meets the project needs. 
To manipulate highly exactitude digital data corresponds to the desire to streamline the process of documentation and architectural production without human intervention. Digital tools can offer a seamless process of data gathering and production with minimal human error in data transcription and translation. ${ }^{7}$ The architectural thought has been preoccupied with the pursuit of objectifying mediums. Since the introduction of computers to the architectural practice in 1950s, for instance, the architectural thought has rapidly inclined to favor the elimination of the irrational and the personal in favor of a universally applicable system of principles and rules based on absolute certainties. According to Bruegmann, the computational operations performed on precisely selected and organized data were perfectly suited to a reductionist understanding of architectural production, "architects had been preparing themselves to welcome such a tool for two centuries. The exactitude of computers in relation to the processing of information, which is ultimately broken down into digital units, would finally eliminate all imprecise or subjective factors."8

In the midst of the domination of the positivist and reductionist approaches in social sciences during the 1950s, Clifford Geertz formulated "thick description." Geertz stated that a thick description of a social action enunciates not only the action, but its context too, in a way that the action becomes meaningful to an outsider. ${ }^{9}$ Geertz focused on the study of human beings and applied thick description to analyze, interpret, and document social actions as cultural signifiers. When Interpretation of Cultures was published in 1973, his book immediately recognized and became an ecumenical theory in social sciences to "free human inquiry from the killing grip of theoretical fixity." 10 Geertz was not against the scientific study of human beings that refuses counting or a structure, but he was opposed to the extensive use of objectifying methods of data collection or statistical records to develop generalizing accounts of the societies and to explain the underlying historical processes. Geertz firmly attested the generalization of social phenomenon across cultures, "[...] the essential task of theory building [...] is not to codify abstract regularities but to make thick description possible, not to generalize across cases but to generalize within them."11

Geertz elicited textual materials as the formal product of thick description. Ethnographers work in the field from months to years, observe the phenomenon in context, analyze their surroundings, distinguish the webs of significance embedded in the social actions, and reflect their analysis, observation, and interpretation through field journals, which culminates in formal types of publication of journal articles, books, and reports. Geertz's seminal essay of "Notes on the Balinese Cockfight" in the Interpretation of Cultures, exemplifies the execution of thick description in an ethnographic study. Based on the fieldwork conducted in an Indonesian traditional village, in 1950s, the essay articulates the mean- 
ing of cockfight in the Balinese culture. The text provides a detailed narrative of the cockfight taken place reflecting on the network of social relationships in kin and village that govern traditional Balinese life. Geertz draws the readers into the life of the village as if they are active participants in the events taken place. The readers vividly experience the anthropological discoveries unfolding through the essay, they also contextualize the rendered social acts in the webs of the social hierarchy of the Balinese culture.

Besides cultural texts, Geertz recognized other representation mediums as modes of thick description. Different communication venues including drawings, films, and museum displays correspond to ethnographic inquiries, yet self-consciousness about these norms lacks in anthropological studies. In this context, Bray's work on the art of naturalist-realist portrait painting to create "thick-descriptions" is one of the few anthropological studies dedicated to elicit the empathetic and sensitive process of long-term observation and contextual interaction in the process of painting. ${ }^{12}$ Bray wrote that the methodological path of naturalist-realist portrait painting and the epistemological concerns during the process carry similar traits with anthropological analysis, which "serve as a method and 'text' in its own right for anthropological analysis." 13 The act of knowing, seeing, and interpreting during the making of a naturalist-realist painting includes a contextual interaction between the painter and the model correspond to the pursuit of contextualizing of social acts in ethnographic work.

Making drawings of the built environment comprises of various levels and sources of interpretation, not unlike empirical and participatory observations in thick descriptive naturalist-realist painting. The act of drawing is a generative process, which is achieved through numerous long sittings in the historic context, allowing architects to relate to the cultural heritage. Architects establish a deep relationship with the architectural fabric over the course of documentation, while analyzing, observing, measuring, and interpreting. Inquirers grasp and render many qualities of the historic material, such as texture, poignant climates, and experiences, which cannot be represented in texts. ${ }^{14}$ The final product of documentation, measured drawing, is a "thick description," since it is a dense visual analysis of the architects' accumulation of the prevailing building elements as well as reflection of their multisensory experiences of the architectural context. Drawing as a record of documentation, furthermore, affords the viewers to relate to the historic setting. It serves to portray the embodied meanings and values in the architectural fabric, but through architects' perception of cultural heritage.

Reflecting on the methodological path to make measured drawings of the built environment as an account of thick description, this essay discusses architectural documentation. The practice of documentation is 
characterized by change, where technological shifts bring new heights to the execution of the fieldwork and to the nature of end products. Documenters utilize a wide circle of products (such as two-dimensional measured drawings, building information models (BIM), and fly-through videos) to meet the project needs. In a digitally crafted architectural culture, where the inquiries are measured with the exactitude of data and technological mediation, however, the act of drawing has been relegated to a narrower focus in the documentation process. It is very significant, therefore, to acknowledge the ramifications of how images of the built environment are created, whether drawing on a piece of paper or mediating through the-state-of-the-art surveying technologies. To look through a lens and to have a digital tool to "make" an image (like digital photogrammetry and three-dimensional laser scanning) involves physical detachment from the heritage setting. However, while making drawings in the field, architects enter a more direct and engaged relationship with the architectural context. The possibility of defining the act of drawing in architectural documentation through the lens of thick description provides a series of discussions of the modus operandi of recording the built environment. Turning back the clock for the architects by hand surveying the historic buildings and structures is a valuable pedagogical exercise but not realistic within the current workforce. ${ }^{15}$ The documentation practice has already transformed and the present workforce is already comfortable with the advanced technological mediums. To define the methodological path of creating thick descriptive measured drawings, both through analog and digital means, however, allows building a self-reflexive analysis of the craft of architectural documentation.

\section{INTERPRETING THE THREE-DIMENSIONAL WORLD THROUGH TWO-DIMENSIONS}

Merriam Webster's states that a measured drawing is "an architectural scale drawing of an existing structure." The measured drawing is a snapshot of the architectural context at the time of documentation, meaning that architects record the dimensional, material, and structural details of the building and delineate these qualities "true to nature." Each drafted line in the plan drawing of the concession building located on the Liberty Island, New York City, New York (Fig. 2), for example, correspond to a cluster of measured points on a structural element, such as a wooden trim or a door opening, where architects carefully collected measurements from the historic surfaces and then transposed their notes to the graphical representation. Creating a commensurable medium of the historic building is the core of architectural documentation since the measured drawing set becomes the reference record for preservation projects. When rehabilitating the facility systems, repairing a historic material, or restoring the building to a significant phase in its life, professionals utilize the information provided through the measured drawings. 
Deconstructing the built environment through two-dimensional mediums is a specific way of understanding the world. Formulating an image of the three-dimensional qualities of a building or site in two-dimensions necessitates projection the surface through plans, sections, and elevations. Architects are trained to create and to analyze depicting the space with two-dimensional drawings as a type of analogy. For example, the plan drawing of the concession building (Fig. 2) is an analogical representation of the real space, where the representation of the window in the plan does not resemble the real one, but gives an idea of its size, proportion, and layout in the room. In this vein, a section drawing (Fig. 3 ) is an imaginary vertical cut through the structure, which architects are educated to develop to disclose the vertical progression of spaces accompanied with structural details, interior decorative finishes, and relation of functions. Elevation drawings include more pictorial emphasis while illustrating facades, room elevations, and other vertical elements of a building (Fig. 1). These drawings show buildings as the architects see them, upright and straight ahead, but without perspective.

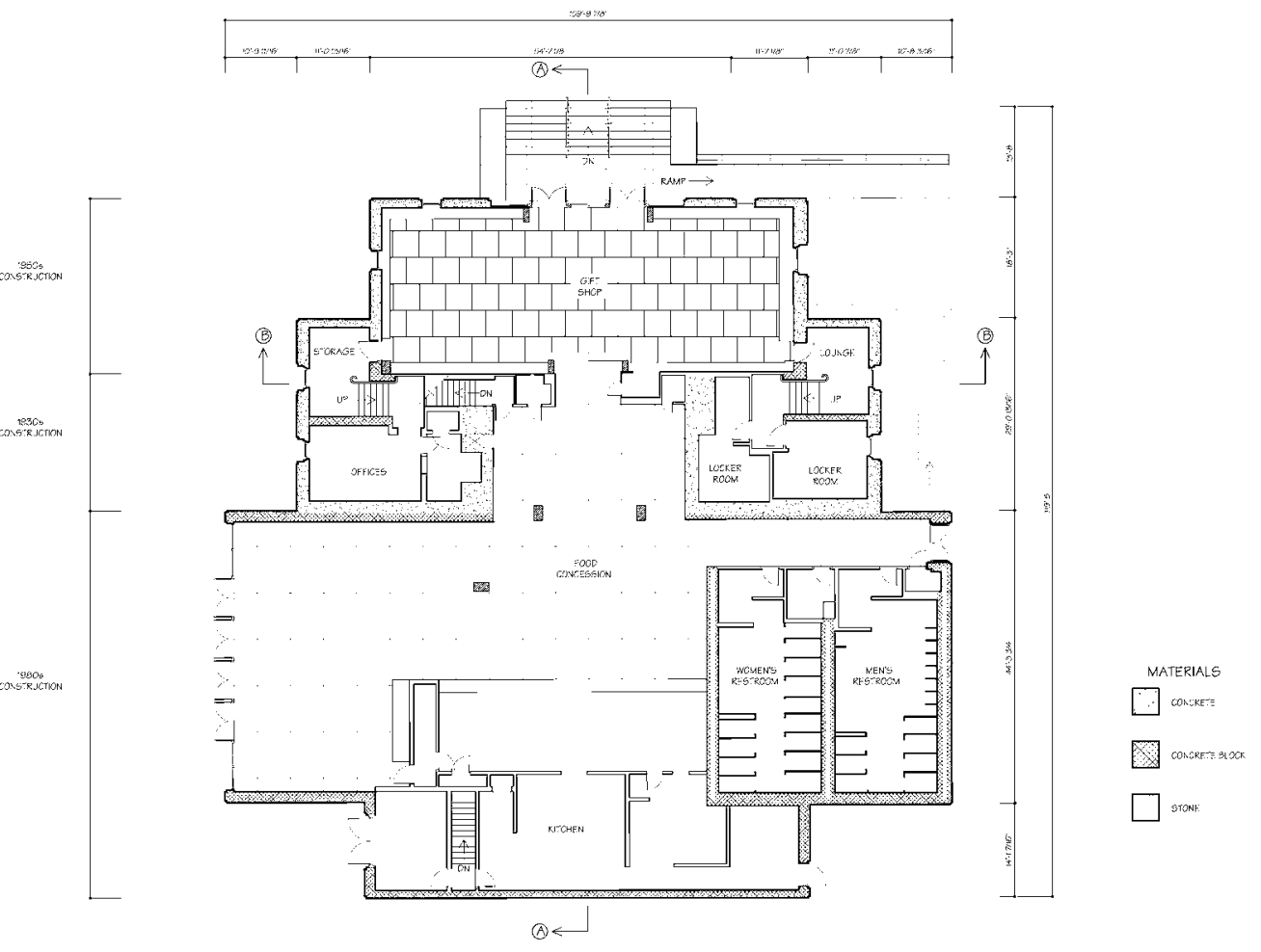

Figure 2. First floor plan drawing of the concession building, Statue of Liberty, Liberty Island, Manhattan, New York County, NY (HAER NY-138-B (sheet 3 of 6)). 
The logical picture of representing the space through two-dimensional mediums is itself analysis and interpretation of the architectural context. The abstraction of the building through horizontal and vertical projections compels the architects to interpret the building characteristics while reflecting on the material, structural, and composition qualities coherently. ${ }^{16}$ The process of continually cutting through the building form and elements allows the inquirers to monitor the consistency of body of materials and ensures that no detail is omitted in the graphical representation. The methodological path of drawing forces architects to peel away individual qualities (such as a frieze detail, a staircase, or a porch) and to augment these characteristics in horizontal and vertical projections collectively. This cognitive process of analysis and interpretation through twodimensional drawings is negotiated through being attentive to the dimension, proportion, and scale of the building features.

Bracketing building details through plans, sections, or elevations, furthermore, renders the architectural context accessible as a graphical account. Similar to Geertz' definition of thick descriptive textual material to dissolve the opacity of the social act, the two-dimensional analytical configuration provides a lens to "read" the architectural fabric. Both involve a process aims to acquire an intimate understanding of what lies beneath the skin of the subject, be it a social act or a building. Just as ethnographers study "a multiplicity of complex conceptual structures, many of them superimposed upon or knotted into one another, which are at once strange, irregular, and inexplicit," and render them through the line of writing; architects effectively capture the architectural, structural, and material qualities in a comprehensible form through twodimensional drawings. ${ }^{17}$ The measured drawings, subsequently, frame the architectural context in a graphical record, which turn the unique visual presence of the building into an account that can be accessed, viewed, and interpreted.

\section{INSCRIBING THE QUALITIES OF THE BUILT ENVIRONMENT}

Identification and documentation of the building elements that make up the built environment necessitates that the architects understand the underlying socio-cultural ground and import embedded in the architectural heritage. A perceptive documentation project, communicates the structure's architectural character among its cultural importance. Inquirers, therefore, utilize multiple data gathering practices such as archival research, in-depth interviews, and questionnaires to be able to recognize the historical facts as well as the inherent values and meanings associated with the cultural heritage. The findings guide the architects to decode the architectural qualities within the cultural context they were achieved and allow them to make informed decisions about the content of measured drawings. Doing so, architects interpret 
certain architectural elements that signify the cultural heritage (such as a detail in the roof-truss system, evolutionary change of a house, or circulation pattern in a school campus) and formulate the layout of the measured drawings (such as extent of the site plan, sequence of the section drawings, or development of detailed-drawings). Magnifying certain qualities of the historic property does not mean that architects have neglected some aspects of the heritage context; quite the reverse, the inquirers interpret that some details are more important to thickly describe the essence of the historic setting.

Geertz characterized written thick descriptive materials as inscriptions of the social act: "The ethnographer 'inscribes' social discourse; [inquirer] writes it down. In so doing, [the ethnographer] turns [the social act] from a passing event, which exists only in its moment of occurrence, into an account, which exists in its inscriptions and can be reconsulted." ${ }^{18}$ Like inscriptions, measured drawings, are products of and reflect conventions for transposing the built environment along with the socio-cultural issues of events, persons, and places into graphical representations. In part, this transpose, involves inevitable processes of selection; architects delineate certain qualities of the architectural context and thus "leave out" others. For instance, the location of the section cut line in a measured drawing is crucial to reveal the characteristics of the building. While architects' decision of the section line amplifies the structural elements that go along the cutting plane, with the same token it omits the rest of the components that fall behind. ${ }^{19}$ Therefore, more significantly, the measured drawings reflect and incorporate sensitivities, meanings, and understandings that the architects gleaned from studying the physical building elements as well as researching the historical facts. Given this, the measured drawings present or frame the buildings in particular ways, corresponding to the described events in its history.

In many cases, architects are tasked with interpreting a non-traditional character or intangible value associated with a building (such as distinctive features of a designed landscape, structural details not legible from the exterior of the structure, or an industrial process). In these instances, the formalized measured drawing set of plans, sections, and elevations may not be sufficient to convey the significant qualities of the heritage environment. Architects, hence, use interpretive drawings. These drawings complement the measured drawing set, but differ from the formalized plans, sections, and elevations since inquirers amplify a certain characteristic not visible to the naked eye or cross-reference associated materials in different drawings to narrate a process. Therefore, in order to maintain clarity, scale could be omitted from the interpretive drawing, where inquirers would pursue diagrammatic schemes, sequential maps, and perspective drawings. ${ }^{20}$ An example of an interpretive drawing includes the axonometric 
projection of the Delta Flight Launch Facility (Minuteman II ICBM Delta Nine) in the Ellsworth Air Force Base, South Dakota, where a minuteman nuclear missile was stored and kept ready for launching during the Cold War (Fig. 4). The drawing includes a sequence of axonometric drawings of the above and underground structures, which is not accessible to observe with the naked eye.

The arrangement of the existing buildings and structures in the form of a measured drawing is a mode of presentation, defined by Langer as "presentational symbolism." ${ }^{21}$ Such pictorial elements present themselves as a whole and operate primarily through shades of meanings, nuances, and connotations that weave them together. In the context of the built environment of the missile facility, for example, the individual structures (the launch support building, the launcher, and the antenna) do not possess independent meanings, but can be understood in the extent of a nuclear facility. The axonometric drawing of the launch support building, consequently, reveals the mechanical, electrical and environmental control equipment: a diesel generator, power distribution equipment, and a fuel tank. These elements were vital to keep the launch facility operating continuously in the case of a nuclear threat. The form of the support building (rectangular in size) and the structural details (built of reinforced concrete), however, was utilitarian in purpose. A similar structure could have been constructed in another military installation and the equipment could be used as a power generator for a different mission. The elements (Fig. 4) of the missile launch complex depicted in the measured drawing, therefore, require to be understood as a whole, symbolized through storing, maintaining, and launching nuclear missiles during the Cold War.

The presentational abstraction concerns perceptual forms. ${ }^{22}$ These forms are non-verbal such as line, color, or sound. Such forms constitute the meaning of a symbol through articulated relationships portrayed in a work of art. A line, for instance, is not an independent unit of meaning, but a cluster of lines in a measured drawing symbolizes an arch, a roof, or a house. These individual elements fuse into a unity based on their function in the whole. Architects condense, magnify, or eliminate the perceptual elements as they revise the semantic boundaries of the architectural fabric. Doing so, they introduce a symbolic meaning to the presentational elements. Take for example the drawing sheet portraying the minuteman nuclear missile facility (Fig. 4). Each line is connected to another to form a total significance: to reveal the operating process of a missile facility. The meaning in this drawing is neither providing "as-built" depiction of the launcher nor supplying the technical details of the mechanical, electrical and environmental control equipment in the launch support building. The meaning, on the other hand, is the depiction of the specialized functions of the structural elements in a missile facility during the Cold War, which was juxtaposed on paper in a semantic order. 


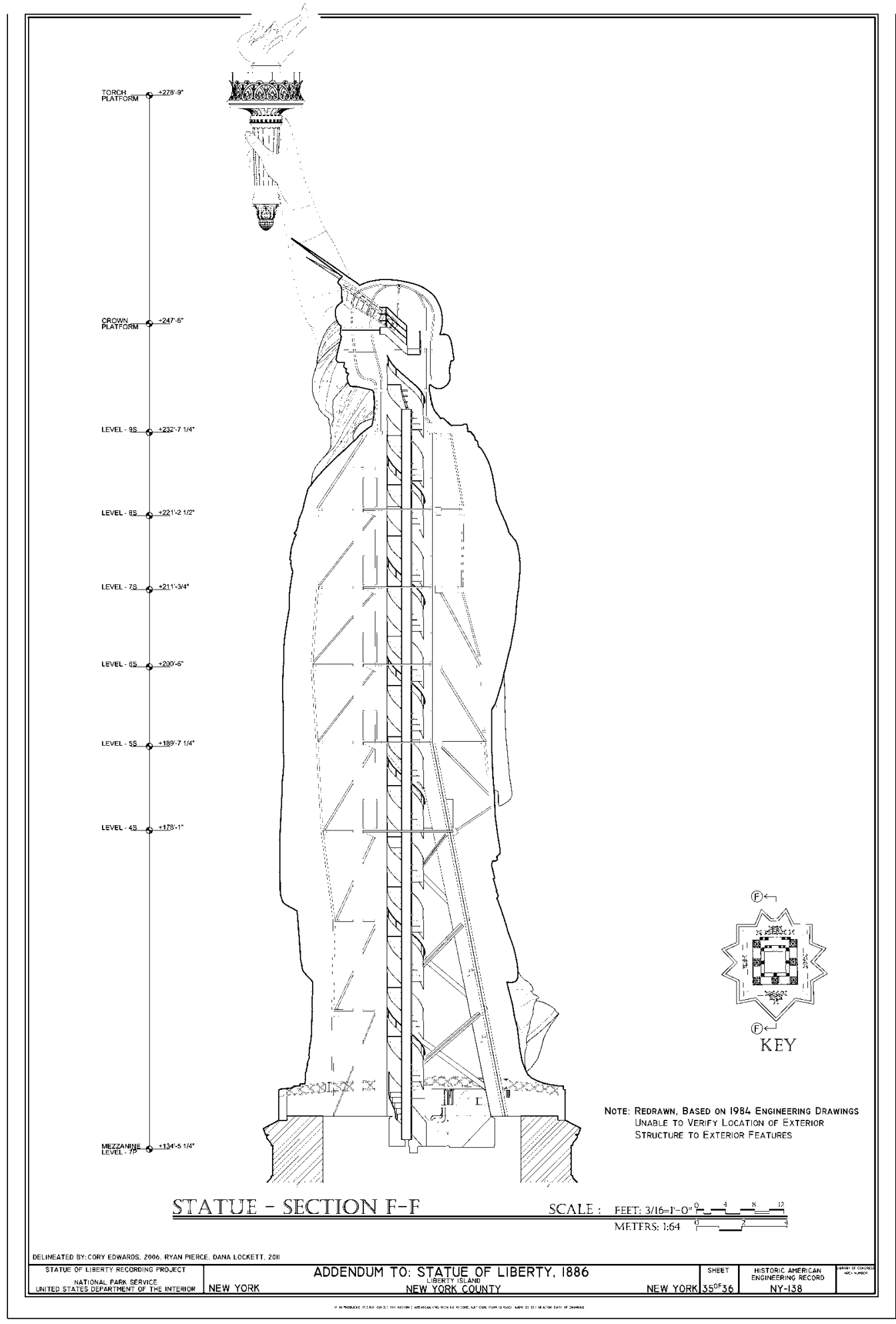

Figure 3. Section drawing of the Statue of Liberty, Liberty Island, Manhattan, New York County, NY (HAER NY,31-NEYO,89- (sheet 35 of 36)). 
The paradigm shift in the documentation discourse from rendering the physical environment through the rigorously formalized as-built measured drawings to the analysis of an intangible character excluding metric information is no different than ethnographers' efforts to provide a thick description of the social phenomena while negotiating the basic analytical systems, refining them through their own observations, and rendering a fair description of the essence of the subject under investigation. On one hand, architects strive to achieve an objective analysis of the built environment using a mathematical prescription of plans, sections, elevations, where inquirers abstract the building materials to acquire geometric precision. Maintaining a level accuracy, accordingly, is utmost important since these records could be used as the basis for preservation treatments of rehabilitation, restoration, and reconstruction. On the other hand, architects correlate unique pieces of information together in a scholarly and interpretive manner, which portray qualities beyond the physical entity. ${ }^{23}$ These two inquiries of the architects, however, merge with the aim to capture the key characteristics of the historic building and to reveal its unique visual presence.

When creating "thick descriptions," ethnographers have to negotiate their interactions with their informants to maintain a fair representation of the social phenomena. Ethnographers often carry out interviews that are semistructured and open-ended, allowing informants to express themselves freely and elicit the issues significant for them. ${ }^{24}$ Inquirers, while decoding informants' narratives, regularly reflect their own presumptions and methodical explorations, as well as field observations and analysis. ${ }^{25}$ Triangulation information from different venues of inquiries focuses on finding multiple perspectives of the social phenomena, but emphasize the informants' narrative as the central place of the study. In these respects, the resulting thick description is a detailed account of the field experiences and interactions with the informants, in which the researchers reveal the patterns of cultural and social relationships and put them in context. ${ }^{26}$

The equivalent to ethnographers' pursuit of amplifying the informants' input would be in measured drawings, the documentation approach of letting the building "speak to" the architects, rather than inquirers' putting their demands on the edifice. ${ }^{27}$ During documentation, architects' first-hand experience with the historic building allow them construct a reading of the key qualities of the built environment. Since every historic building is unique, inquirers' direct observation of the architectural context culminates in utilizing the drawing methods they feel appropriate to dissolve the opacity of the resource. The elevation drawing of the cliff dwelling of the Montezuma Castle (Fig. 1), for example, demonstrates the structure within the natural alcove it is located. The monumental structure was built to make it difficult for enemy tribes to penetrate the natural defense of the vertical barrier. The delineator's careful use of drafting techniques such as stippling accompanied with intense shading and different line weights 


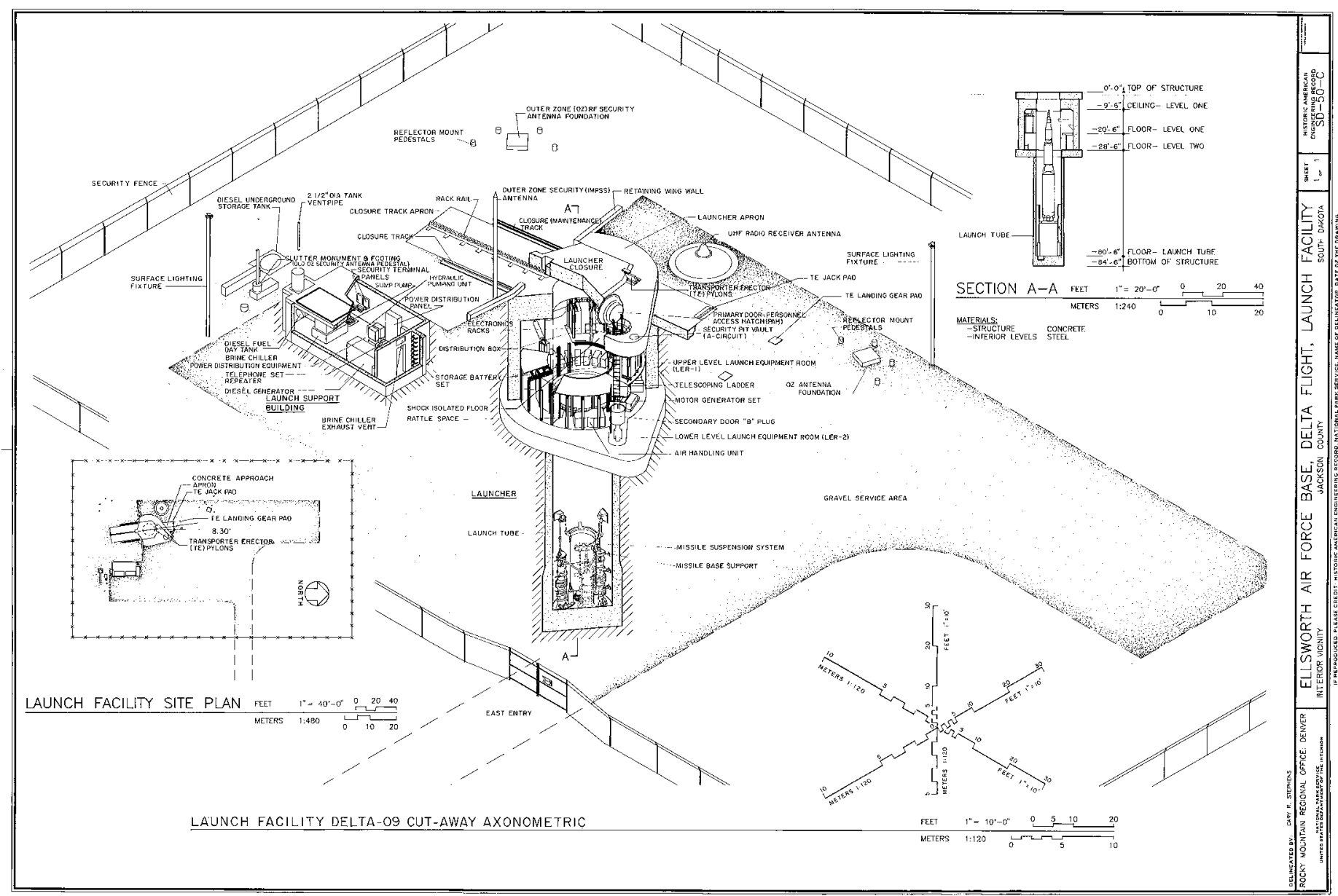

Figure 4. The axonometric drawing of the Delta Flight Launch Facility (Minuteman II ICBM Delta Nine) in the Ellsworth Air Force Base, South Dakota (HAER SD-50-C (sheet 1 of 1)).

captures the textural changes of this monumental dwelling and "brings forward" the dwelling from the rest of the cliff. The axonometric projection of the missile launch facility the Ellsworth Air Force Base (Fig. 4), on the other hand, focuses on the process of storing and launching a nuclear weapon, which characterized the armament deals during the Cold War. Rather than eliciting the architectural appearances, delineator carefully demonstrates the relationship between different buildings in the campus and gets the viewers eye inside individual facilities where the missile was maintained.

In both ethnography and architectural documentation, the thick descriptive records focuses on eliciting specifics of culture rather than searching for universal leads. Geertz firmly detested that ethnographers cannot make assumptions of the characteristics of the subject to construct general explanations across cultures. ${ }^{28}$ Every society inhabits distinct worlds governed by different assumptions, concepts, and socio-historically constructed forms of life. The search for homogenized answers for cultural forms, meaning that applying objectifying reductionist research 
methodologies to study human acts, would only provide an imperfect understanding of the phenomenon. ${ }^{29}$ The plurality of human forms, such as art, architecture, politics, religion, ritual exchange, social thought cannot be relegated to an abstract universal definition. A distinctive characteristic of an art form, for example, is variously embedded in the collective social activities and forms of life that it shapes, but also by which it is shaped. ${ }^{30}$

Similarly, during documentation, architects focus on the building. Every historic structure is unique and inquirers concentrate on the identification and documentation of the stratified changes occurred over the course of time. For example, the concession building on the Liberty Island (Fig. 2), built c. 1930s, at first sight, could be considered as a rudimentary architectural example to accommodate the needs of the patrons visiting the Statue of Liberty on the island. A closer look to the functional layout the building and the changes in material patterns reveal that, however, the current configuration of the historic building is a result of two major expansions undertook in 1950s and 1980s. The offices and the locker rooms belong to the original building of the 1930s, whereas the gift shop expansion was executed in the 1950s, and the food concession accompanied with the restrooms and the kitchen were added in the 1980s. General assumptions of this property like stating its architectural form and pattern as common for each concession building or postulating its evolutionary pattern as the de-facto design of the entire architectural resources constructed in 1930s, cannot be made. The concession building has been distinctly shaped due to its existence on the Liberty Island and its accommodation of the visitors.

\section{CRAFTING THE MEASURED DRAWINGS WITH TECHNOLOGICAL MEDIUMS}

When making measured drawings of the built environment, architects use the artifact as the point of departure to put the historic building in context, to know more about peer resources, and how they relate to each other. To collect accurate data from the building surface, however, architects rely on technological mediums. The traditional toolbox of architects is no different than Le Corbusier's utilization of the tape measure, pen, and paper hundred years ago. To measure a colonnade, for example, the inquirer holds the tape measure against each feature on the surface and writes down the measurements on paper. In most documentation projects, the historic surfaces would not be level resulting that the inquirers cannot use the floors or the walls as the horizontal or vertical planes to gather the field data. Architects, subsequently, would establish datum lines and planes around the building. By leveling a taut string with a carpenter's spirit level around the structure, inquirers can establish the datum line to locate the measurement points geometrically. Often the datum box would be composed with right angles such that simplified drafting the details. Inquirers would triangulate a linear dimension or a line segment on the 
historic surface using the position of the geometric points on the datum line.$^{31}$ Within the known points of the datum box, architects would capture point positions and linear dimensions relative to building elements and other important dimensions on the structural surface.

The conventional approach of surveying includes intensive manual labor, which culminates in architects' immersion in the built environment, during the weeks to months long fieldwork. In the field, inquirers collect information directly from the surface meaning that they have to touch the surface and even crawl under the buildings or build a head for heights. The hands-on experience is vital to acquire a better understanding of the heritage environment because the manual process allows documenters to discern building materials and construction technology while observing changes in the structure. ${ }^{32}$ Architects' contextual interaction with the built environment, therefore, is a process of analysis and interpretation where inquirers constantly capture and deconstruct a body of materials and establish the webs of significance between the elements that will furnish the basis for drawings. Observing the physical details and re-organizing the measures as a whole, demands careful scrutiny and observation skills on the inquirers' part. Subtle details (such as an original wallpaper piece, a ghost window, or a structural crack in the wall) critical to present the essence of the cultural heritage often come to light as inquirers immerse in the architectural setting observing, analyzing, and taking notes. ${ }^{33}$

The use of advanced surveying technologies such as digital photogrammetry and three-dimensional scanning in the field, hence, challenges the architects' contextual interaction with the built environment, which is essential for field analysis and investigation. The automated data collection eliminates the manual process of producing field notes as well as sketching and hand measuring. The conventional way constructing a datum box around the building to check the perpendicularity of the walls or the levelness of the floor is not preferred in the current surveying practice either, since the automated data provides a virtual replica with accurate base information. Figure 5, for example, demonstrates a digital three-dimensional surrogate of the remains of an early Byzantine church building located on the Boğsak Island, Mersin, Turkey. The image was developed using photogrammetry, which is the art and science of obtaining measurements from photographs. Located meters away from the surface, the acquisition of the digital photographs took only a couple of hours labor while the post-process of the photogrammetric data required a weeklong office work. The base information can now be used to produce an elevation drawing of the historic structure, determine the section cut, and acquire metrics for the slope of the island.

The data hierarchy in a photogrammetry project requires a workflow from two-dimensional photographs to a three-dimensional model. Using a digital camera, documenters capture the details on the structural surface while 
positioning the camera shots within tolerances of stereo pairs meaning that the ratio of distance between shots to distance of object is on the order of $1 / 4$ to 1 . The photogrammetry software triangulates the mutual points on the photographic overlays and creates a three-dimensional model. The users utilize the model for many deliverables, such as a template for an elevation drawing or a virtual surrogate for a colonnade. Photogrammetry is a useful surveying strategy for vertical surfaces (sections and elevations) and straight-on details. When recording colossal architectural examples with organic forms, as in the case of the Montezuma Castle in Arizona, documenters merge diverse surveying practices. Since much of the detailing is too high up from the ground to be photographed, to produce the elevation drawing of the Castle (Fig. 1), documenters used a total station to acquire the coordinate points on the stone surfaces, photogrammetric data to obtain the templates for the drawings, and hand surveyed the structure.

Laser scanning, on the contrary, reversed the documentation workflow by promoting the three-dimensional virtual point as the normative field record. A scanner captures the three-dimensional data of a subject by use of rapid range measurement. The tool captures thousands of discrete points per second in near real time. The resultant three-dimensional mass is called a "point-cloud." Each point has x, y, z Cartesian coordinates, RGB values, reflectivity, and intensity parameters. Documenters register separate point-clouds in one coordinate system to acquire the full coverage of the structure. The scanner software either links the targets or matches coordinate points in the surface geometry to combine the individual pointclouds. After registration, users clip the three-dimensional point-cloud to acquire two-dimensional slices, which are used as the template for the measured drawings. The section drawing of the Statue of Liberty (Fig. 3) and the plan drawing of the concession building (Fig. 2) were generated using three-dimensional scan data.

Three-dimensional scanning revolutionized the documentation work since documenters can record a wide range of architectural resources from single structures to historic landscapes that were cumbersome to undertake with conventional methodologies such as hand surveying and photogrammetric recording. A single structure such as the concession building can be scanned in couple of hours, which drastically contrasts to the weeks long hand-measuring campaign. Compared to meticulous monitoring of the quality of photogrammetric images in the field and to capturing hundreds of stereo-pairs to cover an elevation drawing as such in the church building on the Boğsak Island, a laser scanner instantly provides a three-dimensional point-cloud of the subject. Users observe the progress of the point-cloud in the field and provide additional scans as necessary. For colossal structures with irregular forms, such as the Statue of Liberty, scanning allows the documenters to collect building information remotely. Due to the refraction of the laser beam through air and glass, 
however, scanner gives erroneous results when confronted with high-gloss surfaces as in the case of the gilded torch of the Statue. Then additional surveying practices are required to fill the voids in the scan data.

The use of automating surveying technologies in crafting the measured drawings has resulted in a two-fold effect. First, the utilization of digital technologies has been alienating the architects from the abstract thinking and analytical interpretation skills through two-dimensionality. ${ }^{34}$ When inquirers manually collect measurements, they focus on the point and linear information on the surface. Making field drawings necessitates the inquirers simultaneously organize the extant physical qualities through horizontal and vertical projections. This cognitive process is orchestrated through deconstructing the architectural form and space in relation to dimension, proportion, and scale. The application of advanced surveying technologies such as generating a photogrammetric model in Figure 5, or working with point-clouds, on the contrary, fosters the manipulation of the absolute position of survey points in a virtual model rather than the twodimensional dissection of the building form and space..$^{35}$ When making a photogrammetric model, inquirers concentrate on acquiring a set of photographs to be able to extract the point information necessary to define the surface in a three-dimensional photogrammetric surrogate. Likewise, laser scanning necessitates the users to favor the exactitude of virtual points to produce an accurate three-dimensional model.

Second, the automated data shifted the architects' focus from the building surface to the measuring tool. ${ }^{36}$ When architects construct a datum box around the building and acquire direct measurements with conventional tape measures from the surface, they focus on the physical qualities of the built environment. Every point and line segment collected from the datum line corresponds to an existing feature on the surface. The state-ofthe-art technologies, on the other hand, allow the inquirers to collect field data remotely while promoting the virtual survey points as the basis of the

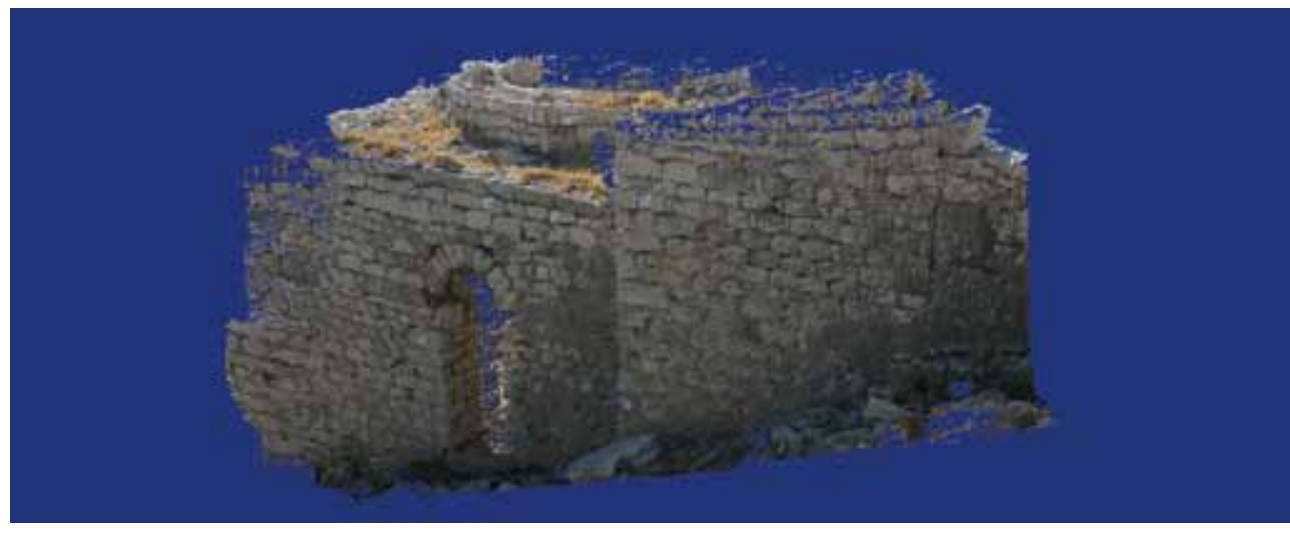

Figure 5. Three-dimensional surrogate of the remains of an early Byzantine church building located on the Boğsak Island, Mersin, Turkey. 
recording practice. Rather than focusing on the building features to gather information, inquirers concentrate on the parameters of the surveying technology to acquire precise virtual points. To be able to generate the photogrammetric model in Figure 5, for example, inquirers monitor the standard deviation in the statistical data and add/remove photographs to improve the quality of the digital surrogate. In this process, besides gathering one measurement from point $A$ to $B$ on the surface of the church to crosscheck the accuracy of the photogrammetric model with the existing dimensions, the documenters did not have to collect surface information. Similarly, while scanning, documenters focus on system parameters such as the range of the scanner, the point density (sampling resolution), and measurement accuracy. Each decision in the system parameters influences the accuracy of the scan data. Documenters scan meters away from the surface without the need to gather field measurements, which save time in the field and increases the safety measures in the working environment.

\section{CONCLUDING THOUGHTS}

Architectural documentation is an intellectual pursuit, where architects are in pursuit of apprehending their surroundings in a way that goes beyond superficial observation and are entitled to produce just more than mediocre representations. On one hand, architects seek ways to understand the built environment, on the other hand they frequently choose between different mediums to best present what they have come to see and recognize. During the process, architects rely on technological mediums (such as pen, paper, digital camera, and computer) to collect dimensional and structural information from the building surface and then sieve their findings to be able to reconstruct the heritage environment in the graphical form. Insisting that recording the built environment is a process devoid of interpretation and interaction, however, discounts the interpretive frame of architectural documentation and the architects' reasoning of the built environment during the process of documentation.

During documentation, architects delineate as much as possible that can be gained from studying the physical environment, while relating to the distinct forms and values embedded in the architectural context. Either formulating projections of plans, sections, and elevations to depict the architectural form and space, or augmenting interpretive drawings to portray an intangible quality of the built environment, the aim of crafting the measured drawings is to develop a better understanding of the cultural heritage and to take the viewers to the heart of the architectural context. The thick measured drawings, in this context, are graphical inscriptions of the essence of the cultural heritage, but morphed through the architects' understanding of the built environment as well as the drawing conventions of the time. 
Advanced surveying technologies allow architects to collect accurate base information rapidly and remotely. While increasingly preferred in the documentation practice, these methodologies, however, transform the nature of architects' immersion in the architectural setting. The manual recording of a building is a reciprocal process where analysis, interpretation, and representation starts in the field when inquirers place a tape measure on the surface. The inquirers instantaneously begin to mediate the essence of the heritage through horizontal and vertical abstraction and to determine the content of the measured drawings. On the other hand, the advanced surveying applications alienate the architects from the material fabric and dismiss the inquirers' contextual interaction with the heritage environment. The process of collecting field data is distinctly separated from drawing. In the field, inquirers focus on the measuring tool and manipulate the system parameters to acquire an accurate digital model. Making the measured drawings is taken place later, physically removed from the architectural context, through registering the digital survey points as the meaningful parts of the graphical representation.

Geertz promoted thick description to expand the sense of human possibilities. Ethnographers refine the field findings to better make sense of the reality of the people, but the process is negotiated through the methodological path of knowing, seeing, and interpreting. Crafting the measured drawings is no different than the process of creating thick descriptions: the curated product is just as much about important as its process of creation. The hands-on experience of the architects' is essential to build a reading of the multilayered architectural context and to thickly describe these elements in the world of representations. In an architectural documentation field heavily dominated by automating tools where the outcome of the field data is measured through the accuracy of survey points, it is crucial to remember that architects' engagement with the built environment is as significant as representing the material culture. 


\section{Notes}

1. Robert McCarter, "Foreword: We Only Know What We Draw," in Drawing from Practice : Architects and the Meaning of Freehand, J. M. Welton (London; New York: Routledge, Taylor \& Francis Group, 2015), xi.

2. Robert B. Warden and David G. Woodcock, "Historic Documentation: A model of Project Based Learning for Architectural Education," Landscape and Urban Planning, 73(2-3), (2005), 111; McCarter, "Foreword: We Only Know What We Draw": xi; Serra Akboy-illk, "The Nature of Drawing in the Changing Culture of Architectural Documentation," Journal of Architectural and Planning Research, 33, (2016a): 29-44.

3. Warden and Woodcock, "Historic Documentation": 111; Serra Akboy-lilk, "Architectural Documentation through Thick Description," Enquiry, 13 (1), (2016b): 17-29.

4. David G. Woodcock, "Discovery through Documentation: The Investigation of Historic and Cultural Resources," APT Bulletin, 37-44, (2006): 38.

5. Le Corbusier, Towards a new Architecture (New York: Dover Publications, 1986).

6. Warden and Woodcock, "Historic Documentation"; Woodcock, "Discovery through Documentation"; Catherine C. Lavoie, C. C., "The Role of HABS in the Field of Architectural Documentation," APT Bulletin, 4/4 (Special Issue on Documentation), (2010); Serra Akboy, The HABS Culture of Documentation with an Analysis of Drawing and Technology (College Station: Texas A\&M University, 2011); Catherine C. Lavoie, "HABS Documentation in the Digital Age," Change Over Time, 1, (2011); Serra Akboy-İlk, "The Mediated Environment of Heritage Recording and Documentation," Preservation Education \& Research, 6, (2013): 7-23.

7. Warden and Woodcock, "Historic Documentation": 113.

8. Robert Bruegmann, "The Pencil and Electronic Sketchboard: Architectural Representation and the Computer," in Architecture and its Image: Four Centuries of Architectural Representation: Works from the Collection of the Canadian Centre for Architecture, ed. Eve Blau, Edward Kaufman, and Robin Evans (Montreal Cambridge, Mass.: Centre Canadien d'Architecture/Canadian Centre for Architecture; Distributed by the MIT Press, 1989), 141.

9. Clifford Geertz, The Interpretation of Cultures: Selected Essays (New York: Basic Books, 1973).

10. Fred Inglis, Clifford Geertz: Culture, Custom and Ethics (Key Contemporary Thinkers, 2000), 112.

11. Geertz, The Interpretation of Cultures: Selected Essays: 26.

12. Zoe Bray, "Anthropology with a Paintbrush: Naturalist-Realist Painting as 'Thick

Description'," Visual Anthropology Review, 31(2), (2015), 119-133.

13. Ibid: 119.

14. Lydia Nakashima Degarrod, "When Ethnographies Enter Art Galleries," in Museum Materialities: Objects, Engagements, Interpretations, S. H. Dudley (London, New York: Routledge, 2010), 130.

15. Robert B. Warden, "Towards a new era of Cultural-heritage Recording and Documentation," APT Bulletin, 40 (3/4): 5-10, (2009), 7.

16. Antony Moulis, "Le Corbusier's Horizon: Technique and the Architectural Plan," Architectural Theory Review, 8(2), (2003); Mark Alan Hewitt, "Architects, Drawings, and Modes of Conception," in Drawing / Thinking: Confronting an Electronic Age, ed. Marc Treib (London, New York: Routledge, 2008); Akboy-İlk, "Architectural Documentation through Thick Description."

17. Geertz, The Interpretation of Cultures: Selected Essays: 10.

18. Ibid: 19.

19. Akboy, The HABS Culture of Documentation with an Analysis of Drawing and Technology; Akboy-İlk, "The Mediated Environment of Heritage Recording and Documentation."

20. Sally Kress Tompkins, Richard K. Anderson, John A. Burns and Paul D. Dolinsky, "Interpretive Drawings," in Recording Historic Structures, ed. J. A. Burns (Wiley, 2004), 166. 21. Susanne K. Langer, Philosophy in New Key: A Study in the Symbolism of Reason, Rite, and Art (Cambridge: Harvard University Press, 1993).

22. Susanne K. Langer, Feeling and Form: A Theory of Art Developed from Philosophy in a New Key (New York: Charles Scribner's Sons, 1953), 241. 
23. Susan Marie Bopp, The Historic American Buildings Survey and Interpretive Drawing: Using Digital Tools to Facilitate Comprehensive Heritage Documentation, (2014): 11-64. 24. Bray, "Anthropology with a Paintbrush."

25. Robert M. Emerson, Rachel I. Fretz, and Linda L. Shaw, Writing Ethnographic Fieldnotes (Chicago: University of Chicago Press, 1995); Catherine Marshall and Gretchen B.

Rossman, Designing Qualitative Research (Thousands Oaks, Calif.: Sage Publications, 2006).

26. Immy Holloway, Basic Concepts for Qualitative Research (London, Malden, MA, USA: Blackwell Science, 1997), 9.

27. Tanya Komas, Historic Building Documentation in the United States, 1933-2000: The Historic American Buildings Survey, a Case Study (College Station: Texas A\&M University, 2005), 149.

28. Clifford Geertz, Available Light: Anthropological Reflections on Philosophical Topics (Princeton, N.J.: Princeton University Press, 2000), 135.

29. Ibid.

30. Renalto I. Rosaldo Jr., "A Note on Geertz as a Cultural Essayist," in The Fate of

"Culture": Geertz and beyond, ed. Sherry B. Ortner (Berkeley: University of California Press, Representations Books, 1999), 33.

31. Warden, "Towards a new era of Cultural-heritage Recording and Documentation": 9.

32. Catherine C. Lavoie, "HABS Documentation in the Digital Age": 192.

33. Akboy-IIlk, "The Mediated Environment of Heritage Recording and Documentation." 34. Warden and Woodcock, "Historic Documentation: A model of Project Based Learning for Architectural Education;" Akboy-Illk, "The Nature of Drawing in the Changing Culture of Architectural Documentation."

35. Warden, "Towards a new era of Cultural-heritage Recording and Documentation;" AkboyIlk, "The Nature of Drawing in the Changing Culture of Architectural Documentation." 36. Ibid.

\section{References}

Akboy, Serra, and Lucienne Thys- Şenocak. "Kültürel Mirasımızın Dijital Belgelenmesi / The Digital Documentation of Our Cultural Heritage." Yapı Architecture, Design, Culture, and Art Magazine 334, (2009): 112-116.

Akboy, Serra. The HABS Culture of Documentation with an Analysis of Drawing and Technology. College Station: Texas A\&M University, 2011.

Akboy-Illk, Serra. "The Mediated Environment of Heritage Recording and Documentation." Preservation Education \& Research, 6, (2013): 7-23.

- - - . "The Nature of Drawing in the Changing Culture of Architectural Documentation." Journal of Architectural and Planning Research, 33, (2016a): 29-44.

- - - "Architectural Documentation through Thick Description." Enquiry, 13(1), (2016b): 17-29.

- - - "Drawing to Read Architectural Heritage." Drawing: Research, Theory, Practice, Volume 2 Number 1, (2017): 97-116.

Bopp, Susan Marie. The Historic American Buildings Survey and Interpretive Drawing: Using Digital Tools to Facilitate Comprehensive Heritage Documentation, (2014).

Bray, Zoe. "Anthropology with a Paintbrush: Naturalist-Realist Painting as 'Thick Description'." Visual Anthropology Review, 31, No. 2, (2015): 119-33.

Bruegmann, Robert. "The Pencil and Electronic Sketchboard: Architectural Representation and the Computer," in Architecture and Its Image : Four Centuries of Architectural Representation: Works from the Collection of the Canadian Centre for Architecture, edited by Eve Blau, Edward Kaufman and Robin Evans, 369. Montreal Cambridge, Mass.: Centre Canadien d'Architecture/Canadian Centre for Architecture; Distributed by the MIT Press, 1989.

Emerson, Robert M., Rachel I., Fretz, and Linda L. Shaw. Writing Ethnographic Fieldnotes. Chicago Guides to Writing, Editing, and Publishing. Chicago: University of Chicago Press, 1995.

Geertz, Clifford. Available Light : Anthropological Reflections on Philosophical Topics. Princeton, N.J.: Princeton University Press, 2000, doi:9780691049748. 
- - - The Interpretation of Cultures: Selected Essays. New York: Basic Books, 1973.

Hewitt, Mark Alan. "Architects, Drawings, and Modes of Conception" in Drawing/Thinking: Confronting an Electronic Age, edited by Marc Treib. London; New York: Routledge, 2008.

Holloway, Immy. Basic Concepts for Qualitative Research. London; Malden, MA, USA: Blackwell Science, 1997.

Inglis, Fred. Clifford Geertz: Culture, Custom and Ethics. Key Contemporary Thinkers, 2000.

Komas, Tanya W. Historic Building Documentation in the United States, 1933-2000: The Historic American Buildings Survey, a Case Study. Texas A\&M University, 2005.

Langer, Susanne K. Feeling and Form: A Theory of Art Developed from Philosophy in a New Key. New York: Charles Scribner's Sons, 1953.

- - - Philosophy in a New Key: A Study in the Symbolism of Reason, Rite, and Art. Harvard University Press: Cambridge, 1942 (7th print,1993).

Lavoie, Catherine C. "HABS Documentation in the Digital Age," Change Over Time, 1, Fall, (2011).

- - - . "The Role of HABS in the Field of Architectural Documentation." APT Bulletin 4/4, no. Special Issue on Documentation, (2010): 19-24.

Le Corbusier, Charles. Towards a New Architecture. New York: Dover Publications, 1986.

Marshall, Catherine and Gretchen B. Rossman. Designing Qualitative Research. 4th ed. Thousands Oaks, Calif.: Sage Publications, 2006.

McCarter, Robert. "Foreword: We Only Know What We Draw," in Drawing from Practice: Architects and the Meaning of Freehand, edited by J. Michael Welton. London; New York: Routledge, Taylor \& Francis Group, 2015.

Moulis, Antony. "Le Corbusier's Horizon: Technique and the Architectural Plan," Architectural Theory Review, 8, no. 2, (2003): 134-42.

Nakashima Degarrod, Lydia. "When Ethnographies Enter Art Galleries," in Museum Materialities: Objects, Engagements, Interpretations, edited by Sandra H. Dudley. London; New York: Routledge, (2010): 128-42.

Rosaldo Jr., Renato I. "A Note on Geertz as a Cultural Essayist," in The Fate of "Culture": Geertz and Beyond, edited by Sherry B. Ortner. Berkeley: University of California Press, 1999.

Tompkins, Sally Kress, Anderson, Richard K., Burns, John A. and Paul D. Dolinsky. "Interpretive Drawings," in Recording Historic Structures, edited by John A. Burns. Wiley, 2004.

Warden, Robert and David Woodcock. "Historic Documentation: A Model of Project Based Learning for Architectural Education," Landscape and Urban Planning 73, no. 2-3 (2005): 110-19.

Warden, Robert. "Towards a New Era of Cultural-Heritage Recording and Documentation." APT Bulletin 40, no. 3/4 (2009): 5-10.

Woodcock, David G. "Discovery through Documentation: The Investigation of Historic and Cultural Resources," APT Bulletin (2006): 37-44.

\section{Acknowledgments}

I am indebted to Robert B. Warden, RA, Head of Department of Architecture, College of Architecture, Texas A\&M University, David G. Woodcock FAIA, FSA, FAPT, Professor Emeritus of Architecture, Director Emeritus of Center for Heritage Conservation (CHC), College of Architecture, Texas A\&M University, and Elizabeth I. Louden, PhD, Director of Historic Preservation Programs, College of Architecture, Texas Tech University for our discussions on architectural documentation and technological mediation. I would like to thank Günder Varinlioğlu, PhD, Professor, Mimar Sinan Fine Arts University, Director of Boğsak Archaeological Survey (BOGA), for accommodating my research inquiries in the scale of a Byzantine settlement. 


\section{Credits}

Figure 1: Drawing delineated by Rima Al Ajlouni.

Figure 2: Drawing delineated by Susan Bruns and the Author.

Figure 3: Drawing delineated by Cory Edwards, Ryan Pierce, and Dana Lockett.

Figure 4: Drawing delineated by Gary R. Stephens.

Figure 5: Photogrammetric model developed by the Author.

Serra Akboy-illk, PhD, Assoc. AIA, currently works at Versar, Inc. Her work focuses on the documentation of the architectural heritage and the application of the US Secretary of Interior's Standards to preserve the built environment. Serra holds a BArch from Mimar Sinan Fine Arts University, İstanbul, Turkey; a MA in Cultural Heritage Management from Koç University, İstanbul, Turkey; and a PhD in Historic Preservation from Texas A\&M University, College Station, TX, USA. Her dissertation "The HABS Culture of Documentation with an Analysis of Drawing and Technology" investigates the modus operandi of documentation projects through the production of measured drawings and technological mediation. Serra specializes in advanced documentation technologies such as threedimensional laser scanning, digital photogrammetry, and GIS, with an interest in drawing. E-mail: serraakboy@yahoo.com 